\title{
Espaçamento para a Cultura da Mandioca
}

\author{
Mário Takahashi* and Valdir Luis Guerini \\ Instituto Agronômico do Paraná (IAPAR). ${ }^{1}$ Estação Experimental de Paranavaí. Caixa Postal: 564, CEP: 87701 - \\ 970, Paranavaí, PR. Estação Experimental de Palotina. Caixa postal: 69, CEP: 85950-000, Palotina, PR.
}

\begin{abstract}
The present work had the objective of evaluating the effect of different line spacing upon some agronomic parameters of cassava (Manihot esculenta Crantz) culture. The experiment was conducted in county of Palotina, in the west region of Paraná State, Brazil. The studied spacing were 0.8, 1.0, 1.4 e $1.6 \mathrm{~m}$ between lines and $0.6 \mathrm{~m}$ between plants, which rendered population densities of 20,830, 16,660, 13,880, 11,900 and 10,410 plants/ha. For the production of fresh and dry root matter and stem fresh matter, the best space between lines was $1.0 \mathrm{~m}$. The highest number of tuberous roots per plant, obtained with the space of $1.40 \mathrm{~m}$ between lines did not guarantee the highest productivity of root matter/ha. The production of the vegetative portion was not influenced by space between lines.
\end{abstract}

Key words: cassava; Manihot esculenta; spacing; plant populations.

\section{INTRODUÇÃO}

Os melhores espaçamentos e populações de plantas para a cultura da mandioca (Manihot esculenta Crantz) são influenciados pelas diferenças que cada cultivar apresenta na arquitetura da parte aérea e ao formato e distribuição das raízes tuberosas. Acima da população ótima, que proporciona a máxima produtividade, diminui-se o tamanho das raízes (Cock et al., 1977). As melhores populações das plantas também são determinadas pelas condições do solo. Em solos de baixa fertilidade, as plantas apresentam reduzido desenvolvimento da parte aérea e das raízes tuberosas, podendo mostrar, com isso, boas respostas ao aumento da população. Já em solos mais férteis, as plantas por apresentarem maior desenvolvimento, permitem espaçamentos mais amplos. Em populações elevadas aumentou-se a produtividade em raízes, mas reduziu-se o número destas por planta, como também o seu tamanho (Toro \& Atlee, 1984 e Mattos, 1991).
Para Zada \& Becalli (1982), em menores populações, há um maior aproveitamento de fotoassimilados, pois estes começam a translocar-se mais rapidamente das folhas para as raízes ao longo do crescimento da planta. Várias cultivares plantadas de 2.500 a 40.000 plantas/hae colhidas aos 12 meses, mostraram aumento de produtividade em raízes em maiores populações, sendo uma boa característica para fins industriais. Todavia para o consumo de mesa, onde são desejáveis raízes grandes, a melhor população foi de 10.000 plantas/ha para cultivares com a parte aérea ereta e 5.000 plantas/ha, para as ramificadas (Toro \& Atlee, 1984).

O espaçamento pode variar de $1,2 \mathrm{~m} \times 0,8 \mathrm{~m}$ a $0,8 \mathrm{~m} \times 0,5 \mathrm{~m}$ em função do porte das cultivares e da fertilidade do solo, nas condições do estado de São Paulo (Lorenzi \& Carvalho Dias, 1993). $\mathrm{Na}$ Bahia, em solos de baixa fertilidade, as maiores produções de raízes foram obtidas com 16.000 plantas/ha (Mattos et al., 1973). Távora et al. (1982) estudaram em duas cultivares,

\footnotetext{
* Autor para correspondência
} 
populações entre 5.000 a 25.000 plantas/ha e obtiveram a máxima produtividade de raízes frescas com 15.000 plantas/ha. Para Enyi (1973) com a mesma distância entre as linhas de $0,9 \mathrm{~m}$, a produtividade em raízes foram superiores nos espaçamentos entre as plantas de 0,6 a 0,9 m em relação a 1,2 m. A produção de raízes por planta foi maior com $0,9 \times 1,2 \mathrm{~m}$. Com $1,0 \mathrm{~m}$ entre as linhas, não foram observadas diferenças significativas nos espaçamentos de 0,5 m, 0,6 m e 0,7 m entre as plantas (Conceição \& Sampaio, 1979).

Face ao exposto, o objetivo deste trabalho foi avaliar o efeito dos espaçamentos entre as linhas das plantas de mandioca, sobre alguns parâmetros fitotécnicos da cultura, nas condições específicas de solo, clima e cultivar.

\section{MATERIAL E MÉTODOS}

O experimento foi conduzido no município de Palotina, PR, na Estação Experimental do Instituto Agronômico do Paraná, situada a 310 $\mathrm{m}$ de altitude acima do nível do mar, na latitude de $24,18 \mathrm{~S}$ e na longitude $53,55 \mathrm{~W}$.

A cultivar de mandioca utilizada recebe regionalmente as denominações de Mico, Chuamba ou Fécula Vermelha. Apresenta a parte aérea ramificada, raízes com a película corticácea escura e é destinada ao processamento industrial.

Os espaçamentos entre as linhas de $0,8 \mathrm{~m}, 1,0$ $\mathrm{m}, 1,2 \mathrm{~m}, 1,4 \mathrm{~m}$ e $1,6 \mathrm{~m}$ totalizaram cinco tratamentos, delineados em blocos ao acaso, com quatro repetições. A área útil da parcela foi composta de 16 plantas. $\mathrm{O}$ espaçamento entre as plantas em todos os tratamentos foi de $0,6 \mathrm{~m}$.

O plantio das mudas com $20 \mathrm{~cm}$ de comprimento e um ciclo de idade, foi realizado em setembro de 1993 e a colheita, em agosto de 1994.

A análise química do solo da área experimental seguiram as metodologias descritas por Pavan et al. (1992) e os resultados encontram-se na Tabela 1. A análise granulométrica do solo apresentou uma composição de $67 \%$ de argila, $17 \%$ de silte e $16 \%$ de areia.

As temperaturas médias e a precipitação ocorridas durante a realização do experimento, encontram-se na Fig. 1.

Os parâmetros avaliados foram: produção das raízes tuberosas fresca e seca, produções da cepa e da parte aérea frescas, índice de colheita e número de raízes tuberosas por planta. A cepa foi considerada a porção da planta onde as raízes tuberosas ficam aderidas, acrescidas da parte aérea $0,15 \mathrm{~m}$ acima do solo. $\mathrm{O}$ índice de colheita seguiu a relação das massas frescas: raízes tuberosas $\mathrm{x}$ (parte aérea + cepas + raízes tuberosas) $)^{-1}$. A matéria seca das raízes foi determinada através da metodologia descrita por Grossman \& Freitas (1950).

Figura 1. Temperaturas médias e precipitação, durante a realização do experimento.

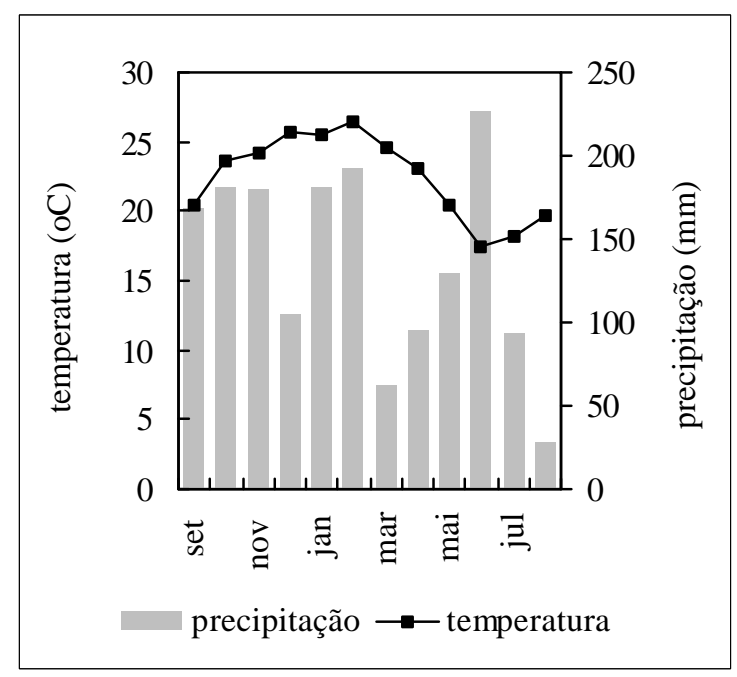


Tabela 1. Resultado da análise química do solo da área experimental, coletado na faixa de 0 a $20 \mathrm{~cm}$ de profundidade.

\begin{tabular}{|c|c|c|c|c|c|c|c|}
\hline $\begin{array}{c}\mathrm{pH} \\
\mathrm{CaCl}_{2}\end{array}$ & $\begin{array}{c}\mathrm{Al} \\
-\end{array}$ & $\mathrm{H}+\mathrm{Al}$ & $\begin{array}{c}\mathrm{Ca} \\
\mathrm{ol}_{\mathrm{c}} / 100 \mathrm{dm}^{3} \\
\end{array}$ & $\mathrm{Mg}$ & $\begin{array}{r}\mathrm{K} \\
---\mid\end{array}$ & $\begin{array}{c}\mathrm{P} \\
\mathrm{mg} / \mathrm{dm}^{3}\end{array}$ & $\begin{array}{c}\mathrm{C} \\
\mathrm{g} / \mathrm{dm}^{3}\end{array}$ \\
\hline 5,1 & 0,0 & 4,07 & 7,65 & 1,07 & 0,45 & 10,0 & 10,8 \\
\hline
\end{tabular}

\section{RESULTADOS E DISCUSSÃO}

A variação dos espaçamentos não influenciou o índice de colheita e o número de raízes tuberosas por planta. As produções da parte aérea e das cepas frescas foram as mais influenciadas pelos tratamentos, seguidas das produções das raízes tuberosas seca e fresca (Tabelas 2 e 3).

Tabela 2. Médias das produções das raízes fresca e seca e das cepas frescas, com os respectivos coeficientes de variação (CV\%) e significância do teste de $\mathrm{F}(\mathrm{P}>\mathrm{F})$.

\begin{tabular}{ccrr}
\hline $\begin{array}{c}\text { Fontes de } \\
\text { variação }\end{array}$ & $\begin{array}{r}\text { Raízes } \\
\text { frescas }\end{array}$ & $\begin{array}{c}\text { Raízes } \\
\text { secas }\end{array}$ & Cepas \\
\hline média & 20,89 & 7,48 & 11,05 \\
CV $(\%)$ & 12,15 & 12,33 & 11,53 \\
P>F & 0,03 & 0,02 & 0,01 \\
\hline
\end{tabular}

Tabela 3. Médias das produções da parte aérea frescas, índice de colheita e número de raízes tuberosas por planta, com os respectivos coeficientes de variação $(\mathrm{CV} \%)$ e significância do teste de F $(\mathrm{P}>\mathrm{F})$.

\begin{tabular}{crcc}
\hline $\begin{array}{c}\text { Fontes de } \\
\text { variação }\end{array}$ & $\begin{array}{r}\text { Parte } \\
\text { aérea }\end{array}$ & $\begin{array}{c}\text { Índice de } \\
\text { colheita }\end{array}$ & $\begin{array}{c}\text { No raízes/ } \\
\text { planta }\end{array}$ \\
\hline média & 19,55 & 40,64 & 5,49 \\
CV $(\%)$ & 9,45 & 6,59 & 7,31 \\
P>F & 0,01 & 0,09 & 0,15 \\
\hline
\end{tabular}

\section{Raízes}

As produções das raízes tuberosas fresca e seca variaram em função do aumento dos espaçamentos, representadas por modelos quadráticos na análise de regressão $\left(\mathrm{r}^{2}\right.$ de $0,96^{*}$ e $\left.0,95^{*}\right)$. As produções máximas das raízes frescas (Fig. 2) e secas ocorreram com 1,0 m entre as linhas, equivalente a uma população de 16.000 plantas/ha, semelhante aos resultados de Mattos et al. (1973). Távora et al. (1982) também obtiveram um ajuste quadrático para a produção de raízes frescas, com a máxima produção no espaçamento de $0,82 \mathrm{~m} \mathrm{x} 0,82 \mathrm{~m}$ e 15.000 plantas/ha. Para Zada \& Becalli (1982), os melhores resultados foram com 18.500 plantas/há, arranjados no espaçamento de $0,9 \times 0,6 \mathrm{~m}$. Estas respostas

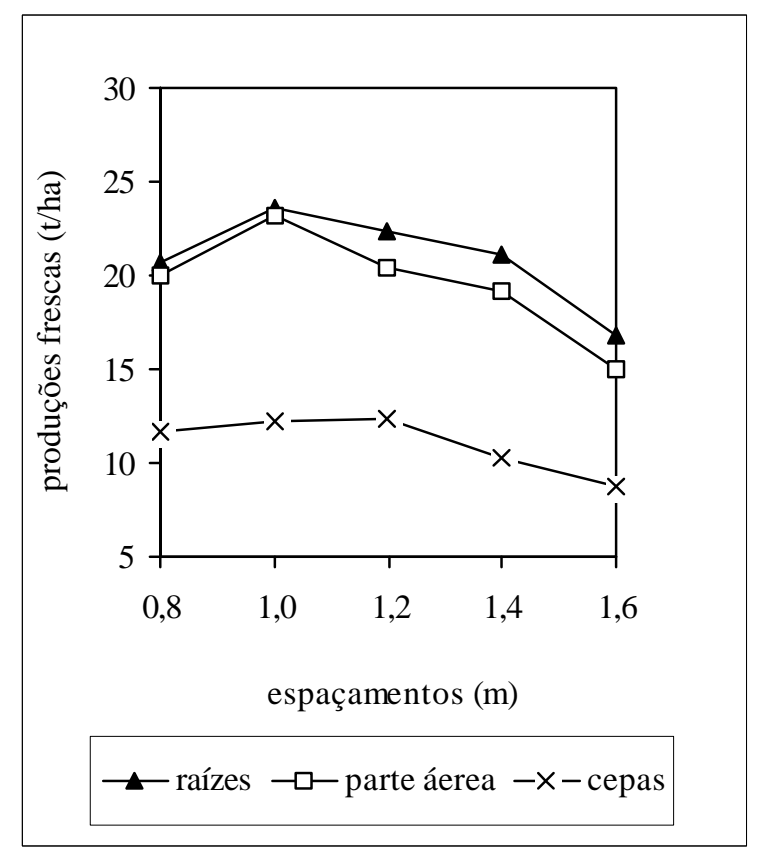

distintas ocorreram principalmente, em função das diferentes cultivares de mandioca utilizadas pelos diversos autores.

A variação observada entre a maior e menor produtividade de raízes foi da ordem de $40 \%$.

Figura 2. Produções das raízes, da parte aérea e das cepas frescas em função dos espaçamentos entre as linhas. 
As produtividades da parte aérea e das raízes frescas apresentaram correlação positiva de 0,97**, apesar que para Zada \& Becalli (1982), quando a planta de mandioca produz um desenvolvimento exuberante da parte aérea, realiza grandes inversões de fotoassimilados para sua manutenção, em detrimento das raízes.

\section{Parte aérea}

A produção da parte aérea fresca apresentou uma resposta quadrática com o aumento do espaçamento $\left(\mathrm{r}^{2}=0,91 *\right)$, diferente da resposta linear crescente obtida por Távora et al. (1982), com populações até 25.000 plantas/ha. A produção máxima foi obtida com 1,0 m entre as linhas (Fig. 2) com de produtividade da ordem de 55\%. As respostas aos espaçamentos são muito variáveis, em função das cultivares e das condições edafoclimáticas.

\section{Cepas}

As produções das cepas frescas foram influenciadas pelos espaçamentos, representada por um modelo de segundo grau com $r^{2}$ de $0,95^{*}$ (Fig. 2). A produção máxima das cepas ocorreu no espaçamento entre as linhas de $1,2 \mathrm{~m}$. Os espaçamentos alteraram a produção das cepas em até $41 \%$.

\section{Índice de colheita}

$\mathrm{O}$ índice de colheita apresentou uma tendência de crescimento linear entre os espaçamentos de $0,8 \mathrm{~m}$ a $1,6 \mathrm{~m}$ entre as linhas, com $\mathrm{r}^{2}$ de $0,81^{*}$ (Fig. 4). Dentro dos limites estudados, a proporção de matéria fresca das raízes em relação ao total produzido pela planta foi crescente, a medida que aumentou-se $o$ espaçamento, mas com diferenças no máximo de 1,9\%. Távora et al. (1982) e Cock et al. (1977) obtiveram resultados semelhantes, com reduções da produtividade das raízes em elevadas populações devido ao decréscimo do índice de colheita.

\section{Número de raízes tuberosas por planta}

O número de raízes tuberosas por planta apresentou uma tendência quadrática com o aumento dos espaçamentos $\left(r^{2}=0,94 *\right)$. No espaçamento de $1,4 \mathrm{~m}$ foi contabilizado o maior número com 4,8 raízes/planta (Fig. 5), mas que não garantiu a maior produção das raízes frescas. A correlação entre o número de raízes/planta e produção de raízes por área não mostrou-se significativa com $\mathrm{r}$ de 0,23 . Em menores populações, Toro \& Atlee (1984) também encontraram maior número de raízes. Para Cock et al. (1977), abaixo de 5.000 plantas/há, reduzem-se as diferenças existentes do número de raízes por planta entre as cultivares, mostrando as variações que a população pode exercer sobre a produtividade.

As respostas aos espaçamentos são portanto, muito variáveis, devido ao comportamento que cada cultivar de mandioca apresenta na

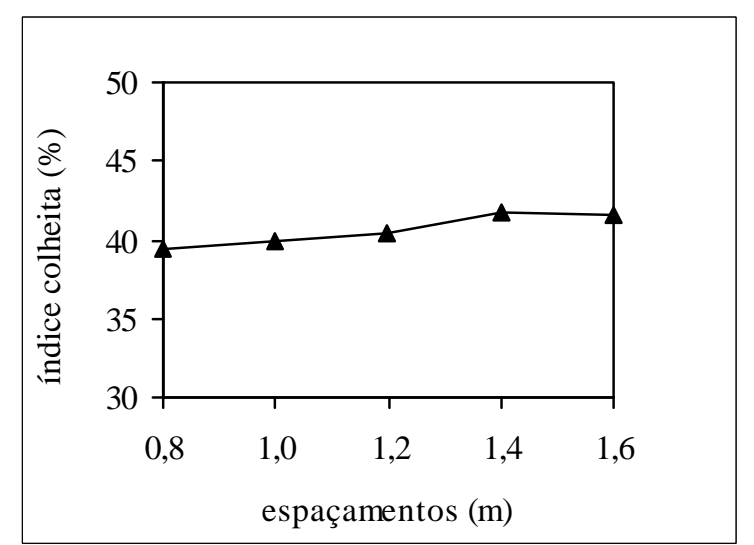

interação com as condições edafoclimáticas.

Figura. 3. Índices de colheita (\%) em função dos espaçamentos entre as linhas.

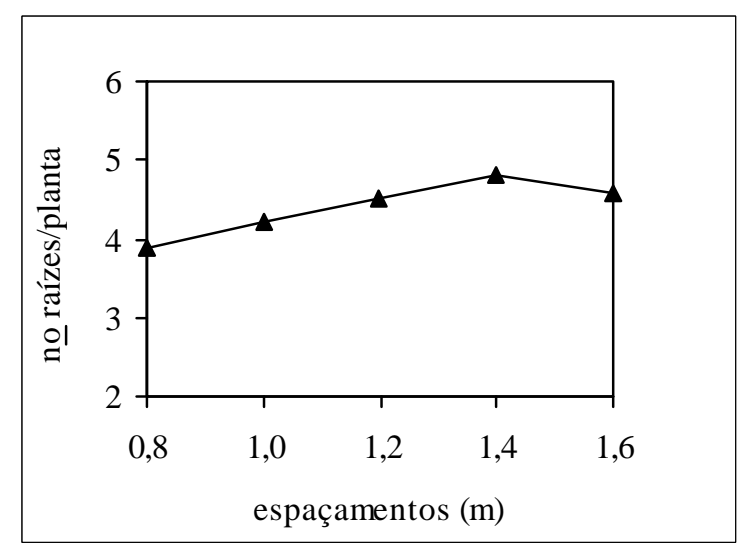

Figura 4. Número de raízes tuberosas por planta em função dos espaçamentos entre as linhas. 


\section{REFERÊNCIAS BIBLIOGRÁFICAS}

Cock, J; Wholey D; De Las Casas, G. O. (1977). Effects of spacing on cassava (Manihot esculenta). Expl. Agric., 13, 289-99.

Conceição, A.J \& Sampaio, C.V. (1979). Influência do espaçamento na cultura da mandioca (Manihot esculenta Crantz). $1^{\circ}$ Congresso Brasileiro de Mandioca, Salvador. Anais..., Sociedade Brasileira de Mandioca.

Enyi, B.A.C. (1973). Growth rates of three cassava varieties (Manihot esculenta $\mathrm{Crantz}$ ) under varying population densities. J. Agric. Sci., 81, 15-28.

Grossman, J \& Freitas, A.C. (1950). Determinação do teor de matéria seca pelo peso específico em raízes de mandioca. Revista Agronômica, 14, 75-80.

Lorenzi, J.O \& Carvalho Dias, C.A (1993). Cultura da mandioca. Boletim técnico no 211 . Campinas. Coordenadoria de Assistência Técnica Integral. 41p.

Mattos, P.L.P. (1991). Espaçamentos para a cultura da mandioca. Mandioca em foco. EMBRAPA. № .97. 2p.

Mattos, P.L.P, Gomes, J.C \& Matos, A.P. (1973). Cultura da mandioca. Cruz das Almas. Instituto de Pesquisas Agropecuárias do Leste. n.27, 13 p.
Pavan, M.A; Bloch, M.A; Zempulski, H.C; Miyazawa, M \& Zocoler, D.C. (1992). Manual de análise química de solo e controle de qualidade. IAPAR,. 40 p. (IAPAR, Circular, $\mathrm{n}^{\mathrm{O}}$ 76).

Távora, F.J.A; Queiroz, G.M; Pinho, J.L.N \& Melo, F.I. (1982). Comportamento de cultivares de mandioca com diferentes características foliares, submetidas a diversas densidades de plantio. Pesq. Agropec. Bras., 17, 417-31.

Toro, J.C \& Atlle, C.B. (1984). Práticas agronômicas para a produção de mandioca: revisão bibliográfica. In: EMBRAPA. Práticas culturais da mandioca: anais do seminário realizado em Salvador, Brasil. Brasília, EMBRAPA-DDT. 245 p (EMBRAPA-DDT. Documentos $\mathrm{n}^{\mathrm{0}}$ 14).

Zada, M.L \& Becalli, E.V. (1982). Influencia de la densidad de población en el rendimiento y crescimiento de las raíces tuberosas de yuca, Manihot esculenta Crantz. Centro Agrícola. 9, 59-67. 